\title{
Spontaneous Remission in Congenital Leukemia AML-M1 with Pericardial Effusion
}

\author{
Ali Bülbül ${ }^{1 *}$, Mesut Dursun ${ }^{2}$, Yıldız Yıldırmak ${ }^{3}$, Bedir Akyol ${ }^{4}$, Umut Zübarioğlu $^{2}$, Ebru Türkoğlu Ünal ${ }^{2}$, Lida Bülbül ${ }^{4}$, Selcen Yaroğlu Kazancı ${ }^{4}$ and Sinan Uslu ${ }^{1}$ \\ ${ }^{1}$ Associate professor in Neonatology, Department of Pediatrics, Division of Neonatology, Sisli Children Hospital, Istanbul, Turkey \\ ${ }^{2}$ Specialist in Neonatology, Department of Pediatrics, Division of Neonatology, Sisli Children Hospital, Istanbul, Turkey \\ ${ }^{3}$ Specialist in Hematology, Department of Pediatrics, Sisli Children Hospital, Istanbul, Turkey \\ ${ }^{4}$ Specialist in Pediatric Cardiology, Department of Pediatrics, Bakirkoy Dr. Sadi Konuk Education and Research Hospital, Istanbul, Turkey
}

*Corresponding author: Ali Bulbul, Associate Professor in Neonatology, Department of Pediatrics, Division of Neonatology, Sisli Children Hospital, Halaskargazi Cad. Sisli, Istanbul, Turkey, Tel: +905052654425; Fax: +902122341121; E-mail: drbulbul1@yahoo.com

Rec date: August 21, 2015; Acc date: September 08, 2015; Pub date: September 12, 2015

Copyright: (C 2015 Bülbül A, et al. This is an open-access article distributed under the terms of the Creative Commons Attribution License, which permits unrestricted use, distribution, and reproduction in any medium, provided the original author and source are credited.

\begin{abstract}
Congenital leukemia is a very rare malignancy of childhood with a poor prognosis. The incidence is nearly 1 in 5 million live births. The majority of cases are acute myeloblastic leukemia with trisomy. Clinical manifestations are usually leukocytosis, petechia, ecchymosis, cutaneous nodules, hepatosplenomegaly and central nervous system symptoms. 23-days old girl was presented with complaints of maculopapular dermatitis and hepatosplenomegaly diagnosed as AML M1. During the follow-up period massive pericardial effusion was detected. This case is presented due to emphasize the rare association of pericardial effusion with congenital leukemia without trisomy and spontaneous remission of leukemia that was occasionally appear in the literature.
\end{abstract}

Keywords: Congenital leukemia; Pericardial effusion; Newborn

\section{Introduction}

Congenital leukemia is a very rare malignancy of childhood with poor prognosis. The incidence is nearly 1 in 5 million live births [1]. Although mortality is high due to aggressive course and complications of the treatment, the two-year survival rate is $23 \%$ [2]. The etiology is unknown but it is assumed that genetic factors, environmental factors, viral infections and immune deficiencies may be responsible [2]. Among many clinical symptoms and signs hepatosplenomegaly, petechia, eccyhmoses and nodular skin lesions may present since birth $[1,2]$. Against childhood, in neonatal period two thirds of the leukemia are originated from myeloid cells. The most defined types are AML M4 and M5 [3]. We report a 23 days old girl who was diagnosed as AML M1 with a rare complication of pericardial effusion.

\section{Case Report}

A full-term female infant was born with spontaneous vaginal delivery at 39 weeks from the first pregnancy of 25 years old healthy mother. Infant was applied to a health center with complaints of fever, swelling and blue to purple color change on the posterior surface of the legs at 18th days of life. She was admitted with the suspicion of sepsis. In the course of hospitalization period hepatosplenomegaly and leucocytosis were detected. Peripheral blood smear revealed atypical cells so he was referred to our hospital with pre-diagnosis of congenital leukemia. At admission she was 23-days-old, 3460 grams in weight, $50.5 \mathrm{~cm}$ in height, $35 \mathrm{~cm}$ in head circumference. Her physical examination revealed phenotypically normal girl with pallor, periorbital hyperemia and edema, ecchymotic lesions and edema on bilateral hands and feet, nearly $2 \mathrm{~cm}$ diameters mobile and solid nodules over the trunk and anterior surfaces of the thighs. Liver was 4 $\mathrm{cm}$ and spleen was $3 \mathrm{~cm}$ palpable below costal margin and $2 / 6$ systolic murmur was heard. Laboratory evaluations were as following: leucocyte count $40410 / \mathrm{mm}^{3}$, hemoglobin $9.2 \mathrm{gr} / \mathrm{dl}$, hematocrit $27.4 \%$,

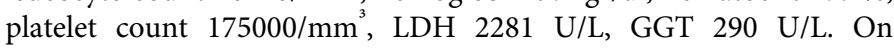
peripheral blood smear there were $20 \%$ blasts (Figure 1). Abdominal ultrasonography was normal except hepatosplenomegaly. Viral serology tests (VDRL, CMV IgM and IgG, Toxoplazmosis IgM and IgG, Rubella IgM and IgG, anti-HIV) were in normal ranges. Bone marrow aspiration yielded $29 \%$ blasts (Figure 2). After flow cytometry analysis (CD7 90\%, CD13 23.8\%, CD33 73.4\%, CD34 64.5\%, CD117 $60.5 \%$, HLA-DR $77.7 \%$, MPO 55.4\%) the patient diagnosed as acute myeloblastic leukemia M1 (AML M1). Bone marrow karyotype analysis revealed chromosome numbers varied between 45 and 47 in 16 of 20 metaphase and in these metaphases trisomy 21 was detected. Cytogenetic analysis were negative for $\mathrm{t}(9 ; 22), \mathrm{t}(15 ; 17), \mathrm{t}(8 ; 21)$, $\operatorname{inv}(16)$.

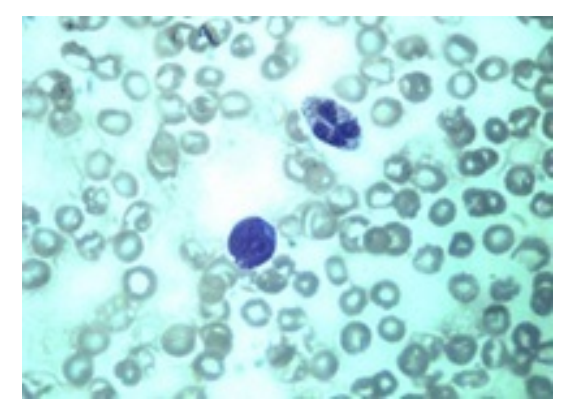

Figure 1: Blast cells seen in peripheral blood smear.

On the seventh day of hospitalization, due to the edema, weight gain, respiratory distress and tachycardia, the fluid therapy of the patient was restricted. She was transfused for anemia. Despite 
erythrocyte transfusion and fluid restriction tachypnea and tachycardia did not resolved so echocardiography had performed showing massive pericardial effusion with normal ventricle size and function (Figure 3). With pericardiocentesis, $7 \mathrm{ml}$, yellow, serous fluid was drained (Table 1). Prednisolone ( $2 \mathrm{mg} / \mathrm{kg} /$ day) and furosemid (1 $\mathrm{mg} / \mathrm{kg} /$ day) was started for treatment of pericardial effusion. Second echocardiography, 24 hours after pericardiocentesis, was normal without any fluid reaccumulation (Figure 4). During follow-up period symptoms had disappeared. At the following 7 th day after pericardiocentesis furosemid was stopped and prednisolone dosage was decreased after normal third echocardiograhy and stopped at 14th day. On the twelfth day of hospitalization laboratory evaluations were found as leucocyte count: $16300 / \mathrm{mm}^{3}$, hemoglobin: $14.9 \mathrm{~g} / \mathrm{dl}$, hematocrit: $41 \%$, platelet count: $342000 / \mathrm{mm}^{3}$. Blasts were detected $10 \%$ in the peripheral blood and $3 \%$ in the bone marrow. Chemotheraphy did not started because the patient accepted as in spontaneous remission. She was discharged from the hospital on postnatal 51st day in clinically and physically stable condition. Karyotype analysis was repeated and resulted as $46 \mathrm{XX}$ without any trisomy during the outpatient visit when she was 2.5 months old so trisomy 21 was excluded. The patient remained without evidence of disease on the last visit when she was 18 months old. She is following up by the pediatric hematology outpatient clinic.

\begin{tabular}{|l|l|l|}
\hline & Pericardial Fluid & Serum \\
\hline Density & 1005 & 91 \\
\hline Glucose (mg/dl) & 99 & 44 \\
\hline Protein (g/L) & 62.7 & 2516 \\
\hline LDH (U/L) & 1152 & \\
\hline Microscopic examination & $\begin{array}{l}\text { Leukocyte: } 1040 / \mathrm{mm}^{3} \\
\text { (\%80 PMNL, \%20 } \\
\text { Lenfocyte) } \\
\text { Erythrocyte: } 1280 / \mathrm{mm}^{3} \\
\text { (no atypical cells) }\end{array}$ & \\
\hline
\end{tabular}

Table 1: Pericardial fluid and serum analysis.

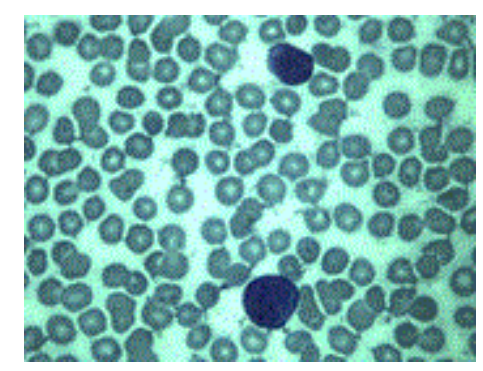

Figure 2: Blast cells seen in bone marrow aspiration.

\section{Discussion}

Despite its rarity, congenital leukemia is the second most observed malignancy of neonatal period [1]. Diagnostic criteria of congenital leukemia are: presenting in the first 4 weeks of the life; increase in immature lymphoid, myeloid and/or eritroid cells; infiltration to the non-hematopoetic tissues and absence of any disease explaining abnormal increasing of the cells [4]. Congenital infections (syphilis, herpes simplex virus, cytomegalovirus, toxoplasmosis), leukemoid reaction, severe erythroblastosis fetalis, transient myeloproliferative disease, congenital HIV infection and neuroblastoma should be considered in differential diagnosis. In congenital leukemia, thrombocytopenia, organomegaly, and leukocytosis may occur in a similar manner with congenital infections. Severe erythroblastosis fetalis can mimic leukemia because both have similar clinical characteristics. Transient myeloproliferative disease may show similar findings with leukemia during newborn and infancy period. Although transient myeloproliferative disease is generally seen in cases of Down syndrome and temporarily causes myeloproliferative disorders in peripheral blood and bone marrow, it can transform into leukemia [5]. In neuroblastoma nodular skin lesions and hepatomegaly may be present as in congenital leukemia [1]. Our patient had anemia and leukocytosis with pallor, hepatosplenomegaly, ecchymoses and noduler skin lesions and viral serology and syphilis tests were normal which may cause leukomoid reaction, abdominal ultrasonography was normal to rule out neuroblastoma.

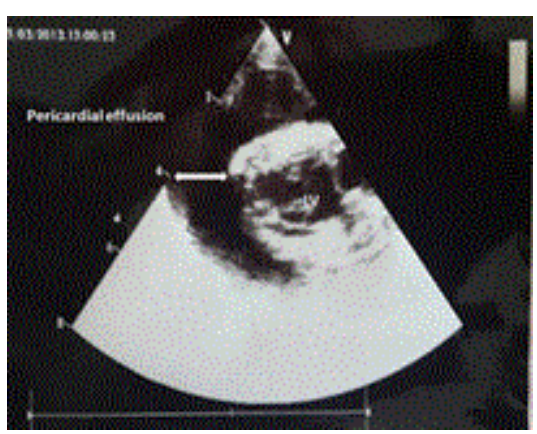

Figure 3: Echocardiogram showing pericardial effusion before pericardiocentesis.

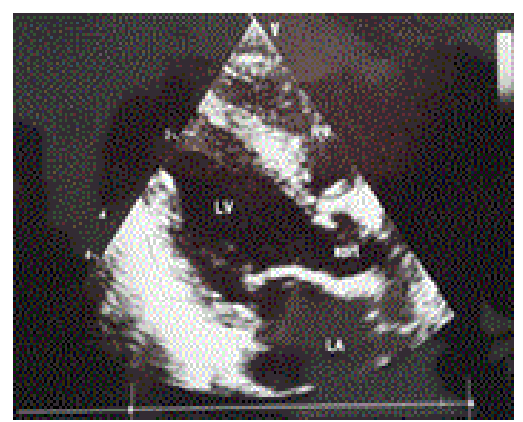

Figure 4: Echocardiogram after pericardiocentesis.

Hepatosplenomegaly is a common finding in patients with congenital leukemia so patients can present with the complaints of abdominal distention and feeding intolerance [2,6]. After invasion of leukemic cells in the liver or if the liver is the primary site of involvement, liver dysfunction may develop. Depending on the liver dysfunction or pericardial or peritoneal dissemination of leukemic cells, ascites or pericardial effusion can be seen in patients with congenital leukemia $[7,8]$. The cases reported in the literature showed 
Citation: Bülbül A, Dursun M, Yildirmak Y, Akyol B, Zübarioglu U, et al. (2015) Spontaneous Remission in Congenital Leukemia AML-M1 with Pericardial Effusion. J Neonatal Biol 4: 196. doi:10.4172/2167-0897.1000196

Page 3 of 3

transient pericardial effusion was associated with generally myelodysplastic syndrome which is defined more in patients with Down syndrome [5,9-12]. In our patient, on the seventh day of admission echocardiography was performed revealing massive pericardial effusion which was treated with pericardiocentesis. Following pericardiocentesis fluid did not reaccumulate. In contrast to literature in our case karyotype analysis was resulted as $46 \mathrm{XX}$ without any trisomy during the outpatient visit so trisomy 21 was excluded.

Although the prognosis of the congenital leukemia is poor, reports on spontaneous remissions in patients with congenital leukemia occasionally appear in the literature [13]. Since organomegaly and skin lesions has resolved and 3\% blast cells were present in the bone marrow, our patient was accepted as being in remission. She was discharged and remaining without evidence of disease at 18 months of age.

As a result, congenital leukemia may present with different clinical signs in the early period of life and the prognosis is poor. Our case was reported because of rare association of pericardial effusion with congenital leukemia without trisomy and spontaneous remission of leukemia that was occasionally appear in the literature.

\section{References}

1. Weitzman S, Grant R (1997) Neonatal oncology: diagnostic and therapeutic dilemmas. Semin Perinatol 21: 102-111.

2. Robbins E, Loh ML, Matthay KK (2012) Congenital malignant disorder (9thedn), Elsevier Saunders, Philadelphia, USA.

3. Torrelo A, Madero L, Mediero IG, Baño A, Zambrano A (2004) Aleukemic congenital leukemia cutis. Pediatr Dermatol 21: 458-461.
4. Resnik KS, Brod BB (1993) Leukemia cutis in congenital leukemia. Analysis and review of the world literature with report of an additional case. Arch Dermatol 129: 1301-1306.

5. Buyukkale G, Cetinkaya M, Akcay A, Payasl ÄM, Oztarhan K, et al. (2012) Transient leukemia-associated pericardial tamponade in a neonate with Down syndrome. Pediatr Hematol Oncol 29: 386-388.

6. McCoy JP Jr, Travis SF, Blumstein L, Birdsall PB, Schroeder K, et al. (1995) Congenital leukemia: report of two cases. Cytometry 22: 89-92.

7. Wu X, Du L, Wang X (2011) Congenital monoblastic leukemia presenting as jaundice, pleural effusion, and ascites: case report and literature review. Fetal Pediatr Pathol 30: 27-31

8. Lewis MS, Kaicker S, Strauchen JA, Morotti RA (2008) Hepatic involvement in congenital acute megakaryoblastic leukemia: a case report with emphasis on the liver pathology findings. Pediatr Dev Pathol 11: 55-58.

9. Azancot A, Diehl R, Dorgeret S, Sebag G, Baumann C, et al. (2003) Isolated pericardial effusion in the human fetus: a report of three cases. Prenat Diagn 23: 193-197.

10. Hirashima C, Eguchi Y, Kohmura Y, Minakami H, Sato I (2000) Isolated pericardial effusion and transient abnormal myelopoiesis in a fetus with Down's syndrome. J Obstet Gynaecol Res 26: 303-306.

11. Mezei G, Sudan M, Izraeli S, Kheifets L (2014) Epidemiology of childhood leukemia in the presence and absence of Down syndrome. Cancer Epidemiol 38: 479-489.

12. Raj A, Talukdar S, Das S, Gogoi PK, Das D, et al. (2014) Congenital leukemia. Indian J Hematol Blood Transfus 30: 159-161.

13. Dinulos JG, Hawkins DS, Clark BS, Francis JS (1997) Spontaneous remission of congenital leukemia. J Pediatr 131: 300-303. 